\title{
Obituary: Liza Maria Veiga (née McCarthy) (October 31, 1963-October 28, 2012)
}

\author{
Adrian Barnett
}

Received: 4 February 2013 / Accepted: 5 February 2013 /Published online: 6 March 2013

(C) Springer Science+Business Media New York 2013

When Liza Veiga died in October 2012 a couple of days short of her 48th birthday, Neotropical primatology lost one of its most productive authors and editors, stoic researchers, able organizers, and enthusiastic teachers.

Liza co-founded the Pitheciine Action Group, a Primate Specialist Group affiliate dedicated to promoting research and conservation of her beloved bearded sakis and their relatives the uacaris and titis; served as a council member of the Brazilian Primatological Society; was an editor for Neotropical Primates; and was the IUCN point of contact for Neotropical primate conservation. She was first editor on Behavioural Ecology and Evolutionary Ecology and Conservation of Sakis, Titis and Uacaris (Cambridge University Press), and was working on this book up to the week she left us.

Based at the Museu Goeldi, in the northern Brazilian coastal city of Belém, Liza taught in the Post-graduate Programme in Animal Sciences at the Federal University of Pará (UFPA), in the same city. There she also coordinated the behavioral ecology study unit. Remarkably for someone with 69 book chapters, 12 journal articles, and 33 conference abstracts, Liza gained her Ph.D. only in 2006, and, more notable still, began working with primates only once she moved to Brazil in 2000. Her first primate publication was in 2004. Before that, after a degree in business economics from the University of Cardiff (1984) and a master's degree in Environment and International Development from the University of East Anglia (1995), Liza worked for Overseas Development Administration. A career change brought a move to France, where she met a Brazilian academic who taught at UFPA. A move to Brazil brought her into contact with tropical forests and, via another translocated Brit, the primatologist Stephen Ferrari, with the region's primates. Ferrari, then teaching at UFPA's Department of Experimental Psychology, recognized in Liza the qualities of dedication, persistence, insight, and organization that a field primatologist requires. Accepted into the Ph.D. programme, Liza scaled the twin learning curves of

\footnotetext{
A. Barnett $(\square)$

Centre for Research in Evolutionary and Ecological Anthropology, Roehampton University, London SW15 4JD, UK

e-mail: adrian.barnett1.biology@gmail.com
} 
Portuguese and Primatology simultaneously, and her thesis (Ecologia $e$ comportamento do cuxiú-preto (Chiropotes satanas) na paisagem fragmentada da Amazônia oriental [Ecology and behaviour of the black bearded saki (Chiropotes satanas) in the fragmented landscape of eastern Amazonia]) appeared in 2006. It was, characteristically, right on time.

From there she swiftly moved across town to the Museu Goeldi, where she began as coordinator for the primate monitoring protocol of Conservation International's (CI) Tropical Ecology Assessment and Monitoring (TEAM) program, before becoming responsible for CI's research at Caxiuan, eastern Brazilian Amazonia. Conducting population viability analysis for the IUCN, from 2008 she was the IUCN Primate Specialist Group's coordinator for the Pitheciines (Callicebus, Pithecia, Chiropotes, and (Cacajao). Liza also made substantial contributions to the IUCN Red Data Book, coordinating the sheets for almost all pitheciine species and detailing their ecology, conservation status, and threats. She also worked with Brazilian government organizations such as MMA (Environment Ministry) and IBAMA (National Parks Service) on national primate conservation plans as well as with Brazilian Primate Centre in Belém, studying the Critically Endangered regional endemic, Cebus kaapori.

Colleagues, co-workers, students, and friends feel the loss of her dynamism, enthusiasm, and organizational power. Many will mourn the mutual projects that will now never have Liza's enthusiastic cooperation to aid their completion. Her passing is a huge loss not only for academic primatology and for all those who knew her, but also for the primates that she loved so strongly and for whose protection she fought with such passion and dedication. 